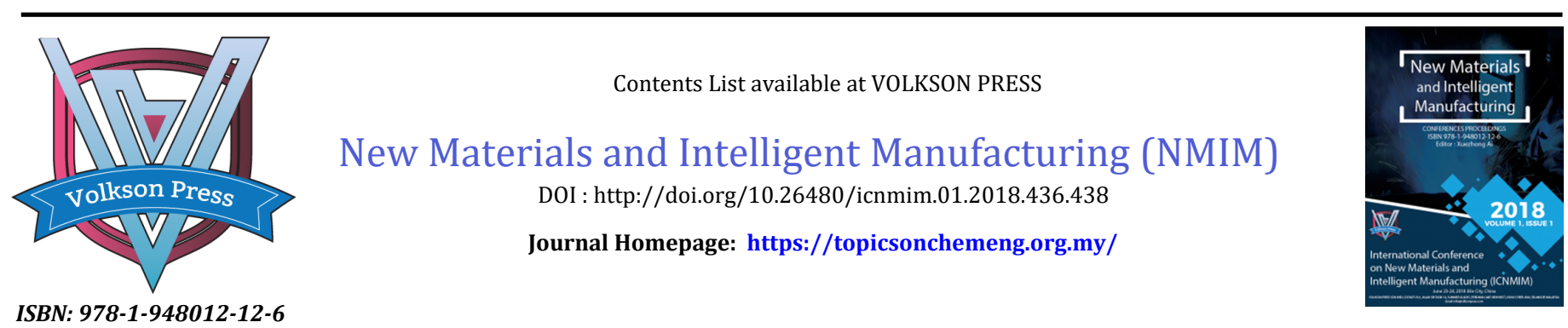

ISBN: 978-1-948012-12-6

\title{
RESEARCH ON GROUNDWATER POLLUTION MIGRATION SIMULATION AND PREVENTION AND CONTROL TECHNOLOGY
}

\author{
Hao Liwen ${ }^{1}$, Tian Ao ${ }^{1}$, Cao Yubo ${ }^{1}$, Yang Ying ${ }^{*}$ \\ ${ }^{1}$ School of Information and Control Engineering, Jilin Institute of Chemical Technology, Chengde Street 45, Jilin, China \\ ${ }^{2}$ School of Petrochemical Technology, Jilin Institute of Chemical Technology, Chengde Street 45, Jilin, China \\ *Corresponding Author E-mail: yangying_1972@163.com
}

This is an open access article distributed under the Creative Commons Attribution License, which permits unrestricted use, distribution, and reproduction in any medium, provided the original work is properly cited

\section{ARTICLE DETAILS}

\section{Article History:}

Received 26 June 2018 Accepted 2 July 2018 Available online 1 August 2018

\section{ABSTRACT}

Groundwater pollution has brought huge and far-reaching impacts to people's lives and production. How to monitor and prevent contaminated groundwater quality is a difficult problem that must be solved in front of environmental workers. Groundwater migration also affects the extent of groundwater pollution. According to the movement of groundwater and the migration of pollutants, prevention and control of groundwater pollution. By simulating groundwater movement, groundwater pollution is analyzed, and groundwater is remotely monitored by a monitoring well using a control system to monitor various parameters at a certain location. If a parameter exceeds the target range, water samples that exceed the standard are extracted and repaired. This paper simulates groundwater monitoring and repair using Kingview software and designs a control system to achieve remote control of groundwater monitoring and repair.

\section{KEYWORDS}

groundwater pollution; migration simulation; prevention and control technology.

\section{INTRODUCTION}

Based on a study, the simulation of groundwater contaminant migration is mainly simulated by mathematical simulation, so as to summarize the migration rule of pollutant concentration [1-4]. In many studies of groundwater pollution, many practical problems, such as groundwater pollution, are involved in the simulation of groundwater migration, the main method used is the convection diffusion method [5-6]. A mathematical model is established to simulate the law of groundwater movement and transport of pollutants. According to the movement of the solute, the monitoring well group is set up, the parameters of the dissolved oxygen, COD, $\mathrm{pH}$ and oil of the wellhead are monitored. Then the process curve of the contaminated water in a certain in-situ well is made, and the parameters of its wellhead are one of the parameters. When the denier exceeds the standard, it is extracted and processed. After treatment, the simulation curve is made again. The degree of water pollution and the changes of the parameters before and after the treatment are compared, so as to achieve the purpose of treatment.

\section{DIGITAL MODEL OF GROUNDWATER POLLUTION MIGRATION}

\subsection{Darcy's law}

Most groundwater movement laws are in accordance with Darcy's law, and they describe the basic laws of water flow in porous media.

$$
Q=-K \omega \frac{h_{2}-h_{1}}{\Delta s}
$$

In the formula: $Q-$ Permeate flow; $K-$ Permeability coefficient; $\omega-$ Cross section; $h_{2}-h_{1}-$ Head loss (difference between the head of the downstream section and the head of the upstream section); $\Delta S-$ Infiltration pathway.

\subsection{Convection - dispersion}

During the movement of groundwater in aquifers, solute moves with groundwater at an average actual flow rate. According to research, this movement, which carries solutes together with groundwater, is called convection of solute [7]. The mass of contaminants contained in a unit volume of groundwater solution, referred to as the contaminant concentration, is denoted as C. The mass of pollutants that pass through the aquifer cross section per unit time is called the flux of pollutants and is recorded as $q_{c}$. Therefore, the flux caused by convection can be expressed as

$q_{c}$

$$
q_{c}=\nu C=n \mu C
$$

In the formula: $v$ is the average flow rate of the fluid through the porous medium, which is called the percolation velocity, ie the Darcy flow rate (LT-1); $\mu$ is the average velocity vector of the fluid passing through the pores of the porous medium, called the penetration rate ( $\left.\mathrm{LT}^{-1}\right)$. Based on a study, the hydrodynamic dispersion of pollutants in porous media consists of two parts, namely molecular diffusion and mechanical dispersion [810]. Molecular diffusion refers to the uneven distribution of pollutants in porous media. Under the effect of temperature, pressure, and concentration, even if they do not flow, pollutants will diffuse from high concentration regions to low concentration regions. Such diffusion is caused by molecules. The phenomenon of particle dispersion caused by random thermal motion exists in all the movement processes of pollutants. The molecular diffusion flux can be described by Fick's first law, that is, the molecular diffusion flux of a contaminant is proportional to its concentration gradient, and the direction of diffusion is opposite to that of the concentration gradient and can be expressed as

$$
q_{d}=-n D_{s} \frac{\partial C}{\partial L}
$$

In the formula, $D_{s}$-dilution coefficient of solute molecules in groundwater $\left(\mathrm{L}^{2} \mathrm{~T}^{-1}\right) ; L$-distance in the direction of diffusion (L). 


\subsection{Convection-Dispersion Equation}

Solute transport equation: a general three-dimensional convection diffusion equation is given.

$$
\frac{\partial(\theta C)}{\partial t}=\nabla(\theta D \bullet \theta C)-\nabla(q C)+q_{s} c_{s}
$$

In the formula, $C$-tracer; $\theta$-effective porosity; $D$-dispersion coefficient; $q$-Darcy velocity; $q_{s}$-source / sink, volume flow of unit volume aquifer; $c_{s}$-unit volume of water, that is, the volume of water released by unit volume at the unit value of head drop.

In the ideal state, the convection diffusion equation of the water storage effect of unsteady groundwater flow field is ignored, that is, $\theta$ is constant, and a coordinate axis coincides with the direction of water flow, which is assumed to be a $\mathrm{X}$ axis and a passive sink. The following is the corresponding convection-dispersion equation.

$$
\frac{\partial C}{\partial t}=D_{\mathrm{xx}} \frac{\partial^{2} C}{\partial \mathrm{x}^{2}}+D_{y y} \frac{\partial^{2} C}{\partial \mathrm{y}^{2}}+D_{\mathrm{zz}} \frac{\partial^{2} C}{\partial z^{2}}-\mathrm{v} \frac{\partial C}{\partial \mathrm{x}}
$$

In the formula, $\mathrm{v}-$ flow velocity.

The finite difference method is used to solve the equation (5). The central difference scheme of the above equation is as follows:

$$
\frac{C_{\mathrm{i}, \mathrm{j}, \mathrm{k}}^{\mathrm{n}+1}-C_{\mathrm{i}, \mathrm{j}, \mathrm{k}}^{\mathrm{n}}}{\Delta \mathrm{t}}=D_{\mathrm{xx}} \frac{C_{\mathrm{i}+1, \mathrm{j}, \mathrm{k}}^{\mathrm{n}}-2 C_{\mathrm{i}, \mathrm{j}, \mathrm{k}}^{\mathrm{n}}+C_{\mathrm{i}-1, \mathrm{j}, \mathrm{k}}^{\mathrm{n}}}{(\Delta \mathrm{x})^{2}}+
$$

$D_{\mathrm{yy}} \frac{C_{\mathrm{i}, \mathrm{j}+1, \mathrm{k}}^{\mathrm{n}}-2 C_{\mathrm{i}, \mathrm{j}, \mathrm{k}}^{\mathrm{n}}+C_{\mathrm{i}, \mathrm{j}-1, \mathrm{k}}^{\mathrm{n}}}{(\Delta \mathrm{y})^{2}}+$

$D_{\mathrm{zz}} \frac{C_{\mathrm{i}, \mathrm{j}, \mathrm{k}+1}^{\mathrm{n}}-2 C_{\mathrm{i}, \mathrm{j}, \mathrm{k}}^{\mathrm{n}}+C_{\mathrm{i}, \mathrm{j}, \mathrm{k}-1}^{\mathrm{n}}}{(\Delta \mathrm{z})^{2}}-\mathrm{v} \frac{C_{\mathrm{i}+1, \mathrm{j}, \mathrm{k}}^{\mathrm{n}}-C_{\mathrm{i}-1, \mathrm{j}, \mathrm{k}}^{\mathrm{n}}}{2 \Delta \mathrm{x}}$

Arrangement:

$$
\begin{aligned}
& C_{\mathrm{i}, \mathrm{j}, \mathrm{k}}^{\mathrm{n}+1}=\left(\frac{D_{\mathrm{xx}} \Delta \mathrm{t}}{(\Delta \mathrm{x})^{2}}-\frac{\mathrm{v} \Delta \mathrm{t}}{2 \Delta \mathrm{x}}\right) C_{\mathrm{i}+1, \mathrm{j}, \mathrm{k}}^{\mathrm{n}}+\left(\frac{D_{\mathrm{xx}} \Delta \mathrm{t}}{(\Delta \mathrm{x})^{2}}+\frac{\mathrm{v} \Delta \mathrm{t}}{2 \Delta \mathrm{x}}\right) C_{\mathrm{i}-1, \mathrm{j}, \mathrm{k}}^{\mathrm{n}}+ \\
& \frac{D_{\mathrm{yy}} \Delta \mathrm{t}}{(\Delta \mathrm{y})^{2}} C_{\mathrm{i}, \mathrm{j}+1, \mathrm{k}}^{\mathrm{n}}+\frac{D_{y y} \Delta \mathrm{t}}{(\Delta \mathrm{y})^{2}} C_{\mathrm{i}, \mathrm{j}-1, \mathrm{k}}^{\mathrm{n}}+ \\
& \frac{D_{\mathrm{zz}} \Delta \mathrm{t}}{(\Delta \mathrm{z})^{2}} C_{\mathrm{i}, \mathrm{j}, \mathrm{k}+1}^{\mathrm{n}}+\frac{D_{\mathrm{zz}} \Delta \mathrm{t}}{(\Delta \mathrm{z})^{2}} C_{\mathrm{i}, \mathrm{j}, \mathrm{k}-1}^{\mathrm{n}}- \\
& \left(\frac{2 D_{\mathrm{xx}} \Delta \mathrm{t}}{(\Delta \mathrm{x})^{2}}+\frac{2 D_{\mathrm{yy}} \Delta \mathrm{t}}{(\Delta \mathrm{y})^{2}}+\frac{2 D_{\mathrm{zz}} \Delta \mathrm{t}}{(\Delta \mathrm{z})^{2}}-1\right) C_{\mathrm{i}, \mathrm{j}, \mathrm{k}}^{\mathrm{n}}
\end{aligned}
$$

\subsection{Groundwater solute migration curve}

(a)

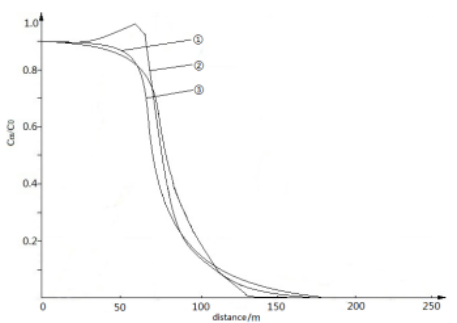

Figure 2: (a) Change in diffusion concentration, (b) Solute migration of solute molecules

As shown in Fig. 2.1, (1)、(2)、(3)is the curve of the solute molecules in three directions with the distance diffusion concentration. Fig. 2.2 is a convective dispersion model simplified by the mass transfer model in the mobile domain and the non-fluid domain. (1)indicates that the porosity is the porosity of the flow field when the mass transfer rate coefficient is close to 0 , and(2)indicates that with the mass transfer coefficient increasing, the porosity becomes closer to the total porosity; (3)indicates that when the transfer coefficient is determined, the time of the porosity reaches the peak.

\section{SAMPLING PROCESS OF CONTAMINATED GROUNDWATER}

According to the groundwater migration model, a suitable well group is established, and then the polluted water in situ is sampled. The flow chart is shown in Figure 3.1.

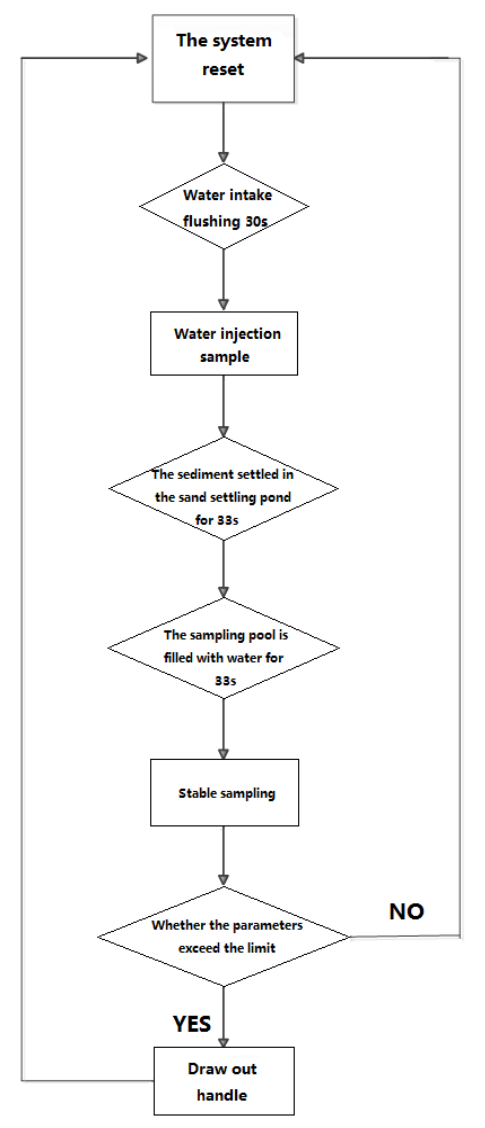

Figure 3: Block diagram of sampling program

\subsection{Application of control system}

According to the sampling situation, it is judged whether the parameters exceed the standard, and if the standard is exceeded, the extraction process is carried out. As shown in Fig. 4.1 and Fig. 4.2, the comparison of the changes in the parameters before and after processing is carried out. Curves 1 to 5 are in situ dissolved oxygen, COD, oil in water, conductivity and $\mathrm{pH}$.

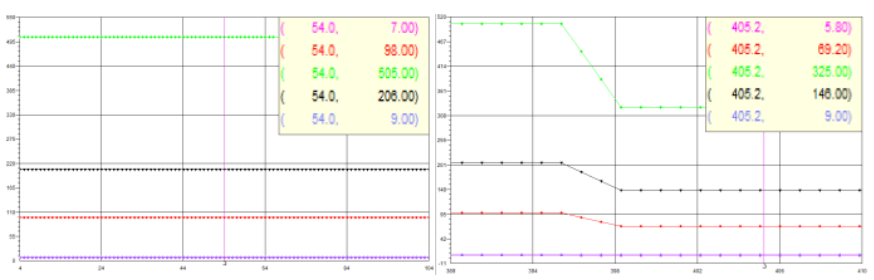

Figure 4.1: Each parameter curve Figure 4.2: Change curves of each before extraction parameter after extraction

\section{CONCLUSION}

The prevention and control system of groundwater pollution has been widely applied in practical projects. There are many methods for monitoring and repairing groundwater pollution in actual research. In this paper, the convection diffusion of groundwater is studied, and the convection diffusion equation is used to solve the equation by the difference method. Then the migration and movement of groundwater are simulated, and the well group is established, and the control system is designed according to the movement of water and the transport of solute. So, it can not only master the pollution of the groundwater. And better handle the effects of pollutants on groundwater. 


\section{REFERENCES}

[1] Bai, F.G., Liu, W., Wen, Yi., Chen, J. 2015. Summary of groundwater solute migration law. Journal of Environmental Protection Science, 41 (06), 86-89.

[2] Zhu, Y. 2013. Study and application of 3-D quasi saturated unsaturated flow and solute transport model in area, Wuhan University.

[3] 2011. Computer simulation of groundwater movement and pollution solute migration. Journal of Environmental Monitoring Management and Technology, 23 (03), 90.

[4] Zeng, X., Zhan, L.T., Chen, Y.M. 2017. Research on analytical simulation of boundary applicability for the analytical simulation of convection and diffusion transfer in low permeability soil column. Journal of geotechnical engineering, 39 (04), 636-644.

[5] Xia, Y., Wu, J.C. 2007. Numerical solution of fractional advection dispersion equation. Journal of Nanjing University (Natural Science Edition), (04), 441-446.

[6] Huang, G.H., Huang, Q.Z., Zhan, R.A., Chen, J., Xiong, Y.W., Feng, S.Y. 2005. Fractional differential convection-Dispersion simulation of pollutant transport in homogeneous medium. Journal of Chinese Science (Earth Science), (S1), 249-254.

[7] Zhang, D.S., Chang, D.P., Bing, S., Wu, X.Q. 2005. Quasi analytical solution of adsorptive solute transport convection diffusion model in soil and its numerical simulation. Journal of hydrodynamics research and progress (Series A), (02), 226-232.

[8] Zhang, P.Y. 2016. Osmotic migration of suspended particles in porous media: pore structure and particle size effect. Beijing Jiaotong University.

[9] Muhammad Yasin, Syed Muhammad Kamran Ali, Munir ul Hassan Munir, Muhammad Ishfaque. 2017. The Sedimentary Geology, Remote sensing, Geomorphology and Petrology of Miocene to Late Pliocene sediments in District Sudhunhoti and Poonch, Azad Jammu and Kashmir, Pakistan. Earth Science Malaysia, 1 (1), 08-14.

[10] Alfarooq O. Basheer, Marlia M. Hanafiah, Mahmood J. Abdulhasan. 2017. A Study on Water Quality from Langat River, Selangor. Acta Scientifica Malaysia, 1 (2), 01-04. 